\title{
Endocrine Mechanisms Responsible for Different Follicular Development During the Estrous Cycle in Hatano High- and Low-avoidance Rats
}

\author{
Sukanya JAROENPORN ${ }^{1)^{*}}$, Yasuyuki HORII',3)*, Sayaka AKIEDA-ASAI ${ }^{4)}$, KaiMing WANG ${ }^{3)}$, \\ Kentaro NAGAOKA ${ }^{2,3)}$, Ryo OHTA ${ }^{5)}$, Mariko SHIROTA ${ }^{6)}$, Gen WATANABE ${ }^{2,3)}$ and \\ Kazuyoshi TAYA ${ }^{2,3)}$
}

\author{
1) Primate Research Unit, Department of Biology, Faculty of Science, Chulalongkorn University, Bangkok 10330, Thailand \\ 2) Department of Basic Veterinary Science, The United Graduate School of Veterinary Sciences, Gifu University, Gifu 501- \\ 1193, Japan \\ 3) Laboratory of Veterinary Physiology, Department of Veterinary Medicine, Faculty of Agriculture, Tokyo University of \\ Agriculture and Technology, Tokyo 183-8509, Japan \\ 4) Frontier Science Research Center, University of Miyazaki, Miyazaki 889-1692, Japan \\ 5) Division of Toxicology, Hatano Research Institute, Food and Drug Safety Center, Kanagawa 257-8523, Japan \\ 6) Laboratory of Comparative Toxicology, School of Veterinary Medicine, Azabu University, Kanagawa 229-8501, Japan
}

\begin{abstract}
Hatano high- and low-avoidance rats (HAA and LAA strains, respectively) were selected and bred according to the avoidance rate in a shuttle-box task. Although they have clear strain differences in ovarian function, their endocrine mechanisms still remain to be clarified. Differences in female reproductive endocrinology between the strains were investigated by means of measuring the plasma concentration of reproductive hormones during the estrous cycle. LAA rats showed approximately threefold lower basal and surge levels of LH, a more than fourfold lower level of FSH surges and higher levels of inhibin A and inhibin B during the estrous cycle compared with the levels seen in HAA rats. The concentration of estradiol- $17 \beta$ in the proestrous stage was significantly lower in LAA rats than in HAA rats. Additionally, LH and FSH secretions from primary cultured anterior pituitary cells with or without in vitro GnRH stimulation were lower in the cells derived from LAA rats and, in terms of FSH secretion, were unresponsive to GnRH in contrast to cells derived from HAA rats. Although an increased number of preantral follicles in diestrus were observed in LAA rats, number of hCG-induced ovulation was lower in LAA rats. LAA rats may have much more follicle growth during the early stage of folliculogenesis, but most follicles might not grow into mature follicles. These results strongly suggest that the strain difference in ovarian function of these two Hatano rats is due to the difference in the regulation of hypothalamo-hypophyseal system for gonadotropins secretion.
\end{abstract}

Key words: Estrous cycle, FSH, Hatano rats, Inhibin, LH

(J. Reprod. Dev. 57: 690-699, 2011)

$\mathbf{I}^{\mathrm{n}}$ order to establish an optimal model for testing the effects of hormones and various xenochemicals, the two inbred strains of Sprague-Dawley rats, known as the Hatano high (HAA)- and low (LAA)-avoidance animals, were genetically selected on the basis of their avoidance rate in a shuttle-box task [1]. Previous studies have shown that the differences in reproductive endocrinology between the HAA and LAA strains are associated with follicular development and luteal functions during the estrous cycle [2, 3]. Thus, the average number of ovulated oocytes on the day of the estrous stage is lower in LAA rats than that in HAA rats, and the length of the estrous cycle is regular at every 4 days in HAA rats but somewhat irregular in LAA rats. Finally, the number of corpora lutea was reported to be greater in LAA than in HAA rats [2] and the surge levels of LH were lower in LAA than in HAA rats. In addition,

Received: October 20, 2010

Accepted: July 18, 2011

Published online in J-STAGE: August 29, 2011,

(C)2011 by The Society for Reproduction and Development.

Correspondence: K Taya (e-mail: taya@cc.tuat.ac.jp)

*S Jaroenporn and Y Horii contributed equally to this study. the FSH surge lasted about 1 day less in LAA rats than in HAA rats on the day of estrus, but the profiles of immunoreactive (ir-) inhibin did not clearly support the patterns of these FSH secretions [2]. Although these differences in ovarian functions during the estrous cycles are probably the result of differences in the activity of the hypothalamo-pituitary-gonadal axis, this remains to be established along with the mechanisms involved. In the present study, the concentrations of circulating $\mathrm{LH}, \mathrm{FSH}$, inhibin A, inhibin B, progesterone and estradiol-17 $\beta$ were measured in association with the follicular development to clarify the endocrine mechanisms responsible for follicular development during the estrous cycle in the HAA and LAA strains of Hatano rats. In addition, the in vitro ability of rat anterior pituitary cells, freshly established as a primary cell culture, to secrete FSH and LH with or without gonadotropinreleasing hormone $(\mathrm{GnRH})$ stimulation was evaluated.

\section{Materials and Methods}

Animals and treatment

Adult female HAA and LAA rats were kept in an animal room 
under standard housing conditions of controlled lighting (lights on 0500-1900 h), temperature $(25 \pm 2 \mathrm{C})$ and humidity $(50 \pm 10 \%)$. They were allowed to feed on rat chow diet (MR-Breeder, Nosan Corporation, Yokohama, Japan) and water ad libitum. Daily vaginal smears were taken to determine the stage of the estrous cycle, and rats with a regular estrous cycle of four days for three consecutive estrous cycles were selected for use in this study. This approach then standardized the two rat strains for a regular estrous cycle, removing the irregularity often observed in LAA rats that would otherwise prevent valid comparisons between the two strains. Blood samples were taken from the jugular vein into heparinized tubes under ether anesthesia every $12 \mathrm{~h}$ from $1200 \mathrm{~h}$ on the day of estrus to $1200 \mathrm{~h}$ on the day of proestrus and then every $6 \mathrm{~h}$ up to $1200 \mathrm{~h}$ on the day of the next estrus. Collected blood samples were immediately centrifuged (1700 $\mathrm{g}$ for $30 \mathrm{~min}$ at $4 \mathrm{C}$ ), and the plasma was harvested and stored at $-20 \mathrm{C}$ until being used for hormonal assays. Another group of the two strains of cyclic Hatano rats were euthanized by decapitation at the same time points as for blood sampling. Anterior pituitary glands were removed immediately after death and homogenized in $5 \mathrm{ml}$ cold saline $(8.5 \mathrm{~g} / \mathrm{l})$. After centrifugation (14000 $\mathrm{g}$ for $30 \mathrm{~min}$ at $4 \mathrm{C}$ ), the resulting supernatant fraction was stored at $-20 \mathrm{C}$ until used for hormonal assays. All procedures were carried out in accordance with guidelines established by the Tokyo University of Agriculture and Technology for use of laboratory animals.

\section{Ovarian histology}

Ovaries from each stage of the estrous cycle, taken at $1200 \mathrm{~h}$ on each day, in both strains were dissected out and preserved in $4 \%(\mathrm{w} / \mathrm{v})$ paraformaldehyde solution for histological examination. The organs were embedded in paraffin wax and then serially sectioned at $5 \mu \mathrm{m}$. The sections were stained with hematoxylin and eosin. Follicles were counted as preantral and antral follicles based on their average diameter, with preantral follicles being defined as those with a diameter smaller than $300 \mu \mathrm{m}$ and antral follicles being defined as those larger than $300 \mu \mathrm{m}$. The average diameters of follicles were determined by averaging the vertical and horizontal diameters that passed through the nucleus of an oocyte with granulosa cells $[2,4]$.

\section{Immunohistochemistry}

Immunohistochemical analysis was conducted according to previously described methods $[5,6]$. Briefly, sections were incubated overnight at $4 \mathrm{C}$ with the primary rabbit polyclonal antibody at a dilution of 1:1000. The three primary antibodies used were (i) polyclonal antibody against [Tyr30]-porcine inhibin $\alpha$ chain (1-30)- $\mathrm{NH}_{2}$ produced at the Laboratory of Veterinary Physiology, Department of Veterinary Medicine, Faculty of Agriculture, Tokyo University of Agriculture and Technology, (ii) polyclonal antibody against synthetic inhibin $\beta$ A chain (\#334-274-ET) and (iii) polyclonal antibody against synthetic inhibin $\beta$ B (\#305-25-D), the latter two being kindly provided by Dr. W. Vale, the Salk Institute for Biological Studies, La Jolla, CA, USA. After incubation with the respective primary antibody in $0.01 \mathrm{M}$ phosphate buffer saline (PBS) at $4 \mathrm{C}$ overnight and then being washed three times with PBS, the sections were then treated with $0.25 \%(\mathrm{v} / \mathrm{v})$ biotinylated goat anti-rabbit secondary antibody (Elite ABC kit; Vector Labs, Burlingame, CA, USA) in PBS at $37 \mathrm{C}$ for $45 \mathrm{~min}$. After washing (as above), these sections were subsequently incubated with $2 \%(\mathrm{v} / \mathrm{v})$ avidin-biotin complex (Elite ABC kit) in PBS at $37 \mathrm{C}$ for $45 \mathrm{~min}$ and washed as above, and then the reaction products were visualized by treatment with $0.025 \%$ (w/v) 3,3'-diaminobenzidine tetrachloride (DAB; Sigma-Aldrich Co., St. Louis, MO, USA) in $0.01 \mathrm{M}$ PBS containing $0.01 \%(\mathrm{v} / \mathrm{v}) \mathrm{H}_{2} \mathrm{O}_{2}$ for $1-20 \mathrm{~min}$ until a brown color developed. The specificity of each primary polyclonal antibody was examined as above but using normal rabbit serum instead of the primary antibody $[5,6]$. In order to identify the structural components and cell types within the ovaries, the sections were counterstained with hematoxylin (Wako Pure Chemical Industries, Osaka, Japan).

\section{Effects of human chorionic gonadotropin (hCG)-induced ovula- tion on diestrus}

Adult female HAA and LAA rats were injected with $200 \mu \mathrm{l}$ of normal saline containing $10 \mathrm{IU}$ hCG hormone (Sankyo Zoki, Tokyo, Japan) into the tail vein at $1700 \mathrm{~h}$ on the day of diestrus under ether anesthesia. The ovaries and oviducts were removed under ether anesthesia in the next morning, and the numbers of ovulated oocytes in the oviducts were counted.

\section{Anterior pituitary cell culture}

Anterior pituitary cells from the dissected pituitary glands of female HAA and LAA rats were dispersed as described previously [7]. In brief, cells at a concentration of $5 \times 10^{4}$ cells $/ 200 \mu$ l were preincubated for $24 \mathrm{~h}$ at $37 \mathrm{C}$ in a humidified atmosphere $(95 \%$ air $/ 5 \% \mathrm{CO}_{2}$ ) with Dulbecco's Modified Eagle's Medium (DMEM; Invitrogen, Burlington, ON, Canada) supplemented with $10 \%(\mathrm{v} / \mathrm{v})$ Daigo's GF21 (inhibin-free serum; Wako Pure Chemical Industries, Osaka, Japan), $100 \mathrm{U} / \mathrm{ml}$ penicillin and $100 \mu \mathrm{g} / \mathrm{ml}$ streptomycin (Invitrogen, Burlington, ON, Canada). After culture for $24 \mathrm{~h}$, the incubation medium was replaced with fresh medium, and then the cells were incubated in the absence or presence of GnRH $\left(10^{-9}\right.$ to $10^{-7} \mathrm{M}$; National Institute of Diabetes and Digestive and Kidney Diseases (NIDDK), Torrance, CA, USA) for $4 \mathrm{~h}$. At the end of the 4-h incubation period, the supernatant was decanted and stored at $-20 \mathrm{C}$ until used for the determination of the LH and FSH levels by radioimmunoassay (RIA). Each experiment was performed in triplicate.

\section{Determination of plasma inhibin $A$ and inhibin B levels by ELI- $S A$}

Plasma inhibin A and inhibin B concentrations were measured with commercial ELISA kits (Serotec, Oxford, Oxon, U.K.) in accordance with the manufacturer's instructions. The characteristics of these dimer-specific assays have been described previously [8]. The evaluated amounts of inhibin A and inhibin B were then expressed in terms of recombinant human inhibin A [9] and recombinant human inhibin B [10], respectively. The intra- and interassay coefficients of variation were less than $10 \%$ and $7 \%$ for inhibin $\mathrm{A}$ and inhibin $\mathrm{B}$, respectively. 
Determination of plasma LH, FSH, estradiol-17 $\beta$ and progesterone concentrations by RIA

Plasma and pituitary levels of LH and FSH were measured using NIDDK rat RIA kits. The antisera used for LH and FSH were antirat LH-S-11 and anti-rat FSH-S-11, respectively. Iodinated preparations were rat LH-I-7 and rat FSH-I-7. The results are expressed in terms of NIDDK rat LH-RP-2 and FSH-RP-2. The intra- and interassay coefficients of variation were 6.4 and $8.6 \%$ for $\mathrm{LH}$, and 6.5 and $7.6 \%$ for $\mathrm{FSH}$, respectively.

Plasma concentrations of estradiol-17 $\beta$ and progesterone were measured by double-antibody RIA using [ $\left.{ }^{125} \mathrm{I}\right]$-labeled radioligands, as described previously [11]. The intra-assay and interassay coefficients of variation were 4.1 and $6.6 \%$ for estradiol-17 $\beta$, and 9.5 and $16.4 \%$ for progesterone, respectively.

\section{Statistical analysis}

Statistical analyses were performed using the Statistical Package for the Social Sciences (SPSS) program (version 11). Data are represented as the mean $\pm \mathrm{SEM}$. An independent $t$-test was applied for comparison of the data between HAA and LAA rats in each period of the estrous cycle. The results of the in vitro experiment were analyzed by two-way ANOVA and then by Duncan's multiple comparison tests. A P value of less than 0.05 was considered to be statistically significant.

\section{Results}

\section{Changes in circulating $L H$}

A surge in the plasma LH levels was observed at $1800 \mathrm{~h}$ during proestrus, and the level returned to its basal levels by $2400 \mathrm{~h}$ of proestrus in both the LAA and HAA strains, but the peak level was significantly (over threefold) lower in LAA rats than in HAA rats (Fig. 1A). In addition, the basal levels of LH were significantly ( $\sim$ threefold) lower in LAA rats than in HAA rats throughout the estrous cycle (Fig. 1A).

\section{Changes in circulating FSH, inhibin A and inhibin B}

The plasma FSH levels abruptly declined from estrus to metestrus, and the basal levels remained until the morning of proestrus in both strains (Fig. 1B). In HAA rats, the plasma FSH levels first surged at $1800 \mathrm{~h}$ of proestrus (the first FSH surge), and this was followed by a second peak at $0600 \mathrm{~h}$ of estrus (the secondary FSH surge) (Fig. 1B). However, in LAA rats, although the first surge of FSH was also observed at $1800 \mathrm{~h}$ of proestrus, it was very weak and had a significantly lower ( 4.5 -fold) peak level than that seen in the HAA rats. In LAA rats, a secondary small peak of FSH was observed at $1200 \mathrm{~h}$ of estrus, but the level was not significantly different as compared with the basal levels (Fig. 1B).

Plasma inhibin A concentrations were at their peak during the periovulatory gonadotropin surges, coinciding with the predicted gonadotropins stimulation for the final follicular maturation in both strains (Fig. 1D). In HAA rats, the plasma concentration of inhibin A fell rapidly to a minimal level at $2400 \mathrm{~h}$ during proestrus and remained at this level until $0600 \mathrm{~h}$ of estrus, a period that coincided with the secondary FSH surge (Fig. 2A). Plasma inhibin A levels then increased at $1200 \mathrm{~h}$ of estrus and continued to rise progres- sively through metestrus, diestrus and the morning of proestrus, peaking at $1200 \mathrm{~h}$ during proestrus. In LAA rats, inhibin A levels did not peak until $1800 \mathrm{~h}$ during proestrus, and although they also fell rapidly by $2400 \mathrm{~h}$ during proestrus, this was to a less marked extent; the levels also tended to increase at $0600 \mathrm{~h}$ of estrus before decreasing again at $1200 \mathrm{~h}$ of estrus. In addition, LAA rats showed a higher peak ( 1.2-fold) and general levels of inhibin A than those seen in HAA rats during the late evening of proestrus and early morning of estrus (Fig. 1D). Inhibin A plasma concentrations were inversely correlated with FSH levels in the HAA rats $(\mathrm{r}=-0.326$, $\mathrm{P}=0.04, \mathrm{n}=40)($ Fig. $2 \mathrm{~A})$, but not in the LAA rats $(\mathrm{r}=-0.202, \mathrm{P}=$ $0.21, n=40)$ (Fig. 2C).

The pattern of plasma inhibin B levels was somewhat broadly similar to that of inhibin $\mathrm{A}$ in the proestrous and estrous stages in as much as the levels declined to a minimal value in mid estrus. However, the transient increase in estrus seen for inhibin A in LAA rats was not evident for inhibin $\mathrm{B}$, and the decline in inhibin $\mathrm{B}$ levels in proestrus began slightly earlier at $1800 \mathrm{~h}$ in both HAA and LAA stains (Fig. 1F). In addition, the levels of inhibin B then rose from late estrus through metestrus (in contrast to the absence of any increase in inhibin A levels in metestrus), and indeed, the plasma concentration of inhibin B exhibited its highest levels at $1200 \mathrm{~h}$ during metestrus in HAA rats or $1200 \mathrm{~h}$ during diestrus in LAA rats before decreasing by $1200 \mathrm{~h}$ during proestrus (Fig. 1D and F). LAA rats showed higher ( 1.7 - to twofold) levels of inhibin $B$ than HAA rats throughout the estrous cycle (Fig. 1F). Inhibin $\mathrm{B}$ was inversely correlated with FSH in the HAA $(\mathrm{r}=-0.564, \mathrm{P}=$ $0.0002, \mathrm{n}=40)$ (Fig. $2 \mathrm{~B})$ and LAA rats $(\mathrm{r}=-0.535, \mathrm{P}=0.0004, \mathrm{n}=$ 40) (Fig. 2D).

During the periovulatory period from proestrus to estrus, a negative corelationship between changes in plasma concentrations of FSH and the two types of inhibin was clearly shown in HAA rats (Figs. 2A and 2B). In HAA rats, the peak of the secondary FSH surge was observed at $0600 \mathrm{~h}$ of estrus, which is when the levels of inhibin A and inhibin B were low, and the plasma levels of the two inhibins abruptly increased at $1200 \mathrm{~h}$ on the same day. In LAA rats, on the other hand, the first surge of FSH finished by $2400 \mathrm{~h}$ of proestrus, and gradually increasing plasma concentrations of FSH were found from $0600 \mathrm{~h}$ to $1200 \mathrm{~h}$ during estrus, though the peak levels were low as compared with that of the first FSH surge (Figs. $2 \mathrm{C}$ and 2D). During the day of estrus, the levels of inhibin $\mathrm{B}$ in LAA rats also gradually increased until $1800 \mathrm{~h}$. The concentrations of both inhibin A and inhibin B in LAA rats at $0600 \mathrm{~h}$ of estrus were significantly high as compared with those in HAA rats (Figs. $1 \mathrm{D}$ and $1 \mathrm{~F})$.

\section{Changes in circulating estradiol-17 $\beta$ and progesterone}

The concentrations of estradiol-17 $\beta$ were low during the estrous and metestrous stages in both the HAA and LAA strains, and the concentrations were similar between the two rat strains (Fig. 1C). In HAA rats, estradiol-17 $\beta$ levels reached a peak at $1200-1800 \mathrm{~h}$ of proestrus. Conversely, the peak level of the estradiol-17 $\beta$ concentration in LAA rats, seen at $1200 \mathrm{~h}$ during diestrus, was significantly (at least twofold) lower than that seen in HAA rats and declined slowly until falling rapidly from $1200 \mathrm{~h}$ during proestrus to a minimal level at $0600 \mathrm{~h}$ during estrus (Fig. 1C). 

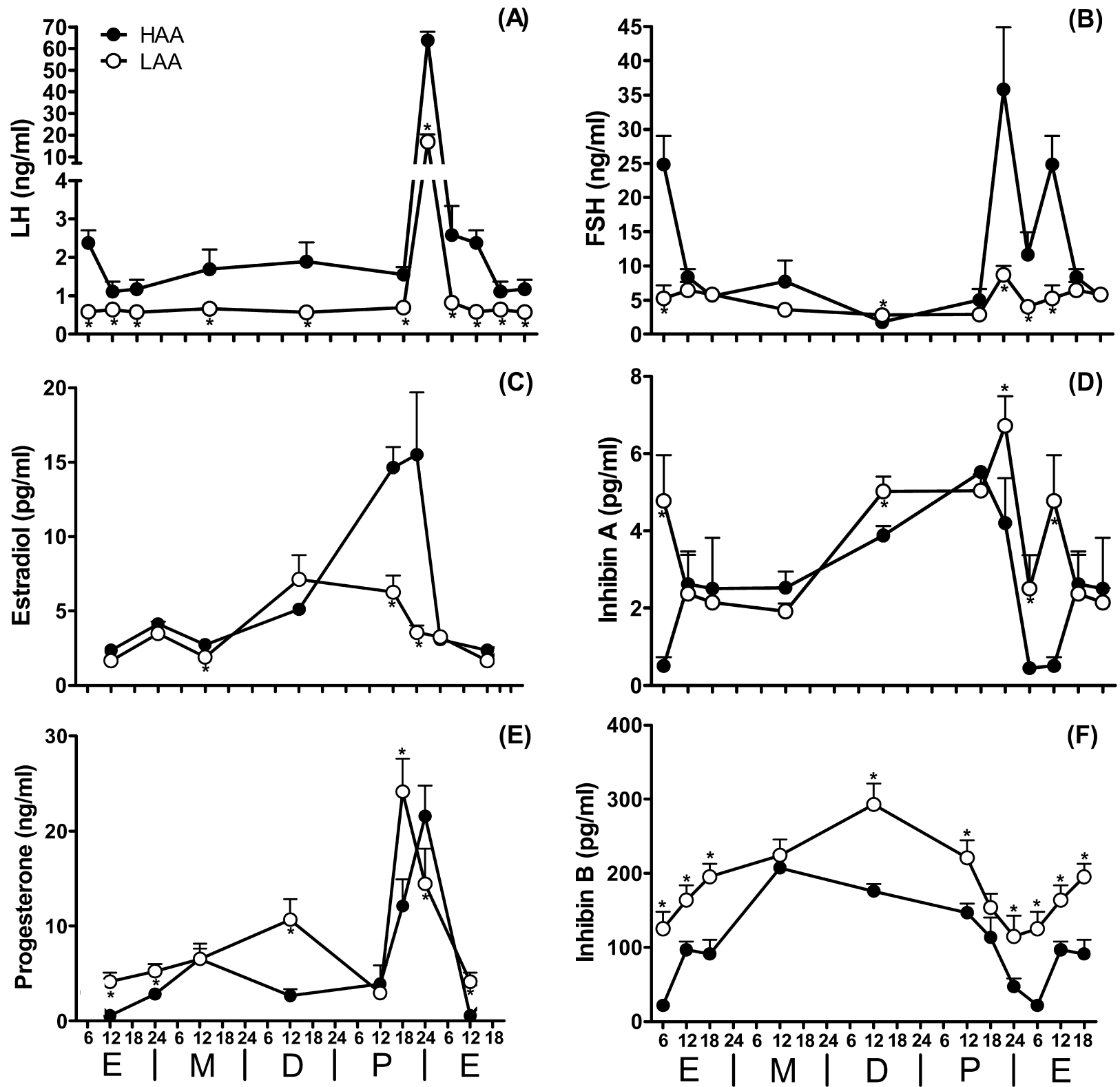

(E)

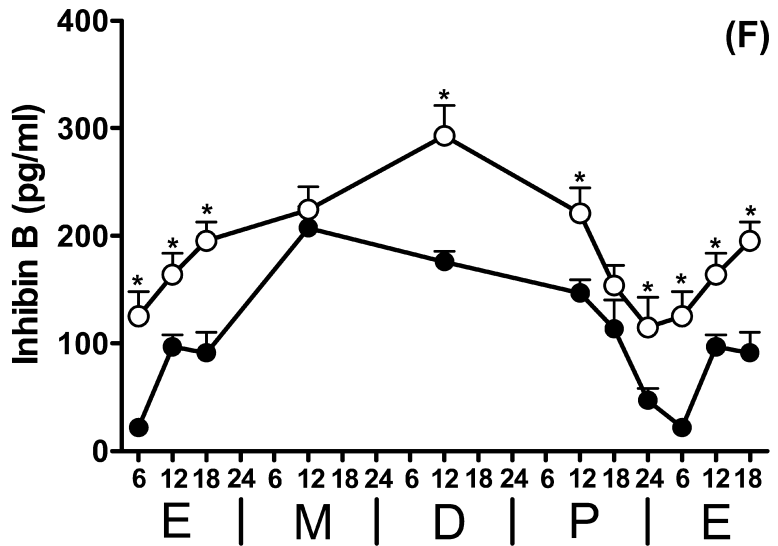

Time and stage of the estrous cycle

Fig. 1. Changes in the circulating concentrations of (A) LH, (B) FSH, (C) estradiol-17ß, (D) inhibin A, (E) progesterone and (F) inhibin B during the estrous cycle in $(\bullet)$ HAA and ( $($ ) LAA rats. Data are shown as the mean \pm SEM and are derived from five rats. * $\mathrm{P}<0.05$ for LAA compared with HAA rats (independent $t$-test). The stages of the estrous cycle are shown as $\mathrm{P}$ for proestrus, $\mathrm{E}$ for estrus, M for metestrus and $\mathrm{D}$ for diestrus.

Progesterone levels fluctuated in a weakly biphasic pattern during the estrous cycle in both the LAA and HAA strains, but with different timings and concentrations (Fig. 1E). A clearly defined peak occurred at $1800 \mathrm{~h}$ during proestrus in the LAA strain, whilst it did not occur until $2400 \mathrm{~h}$ during proestrus in the HAA rats, by which time it was already declining rapidly in the LAA rats. Thus, the progesterone concentrations were significantly different at each time point in estrus between the LAA and HAA rats, even though the peak level was not significantly different. In both rat strains, the peak progesterone concentration was followed by an abrupt decline by the afternoon (LAA) or evening (HAA) of estrus. In HAA rats, a second smaller peak was found at $1200 \mathrm{~h}$ during metestrus, whereas, although it increased in metestrus in the LAA rats, it was not maximal until $1200 \mathrm{~h}$ of diestrus. Regardless, the peak progesterone concentrations in metestrus (HAA) and diestrus (LAA) were significantly lower ( $\sim 3.5$-fold and $\sim 2$.2-fold, respectively) than 

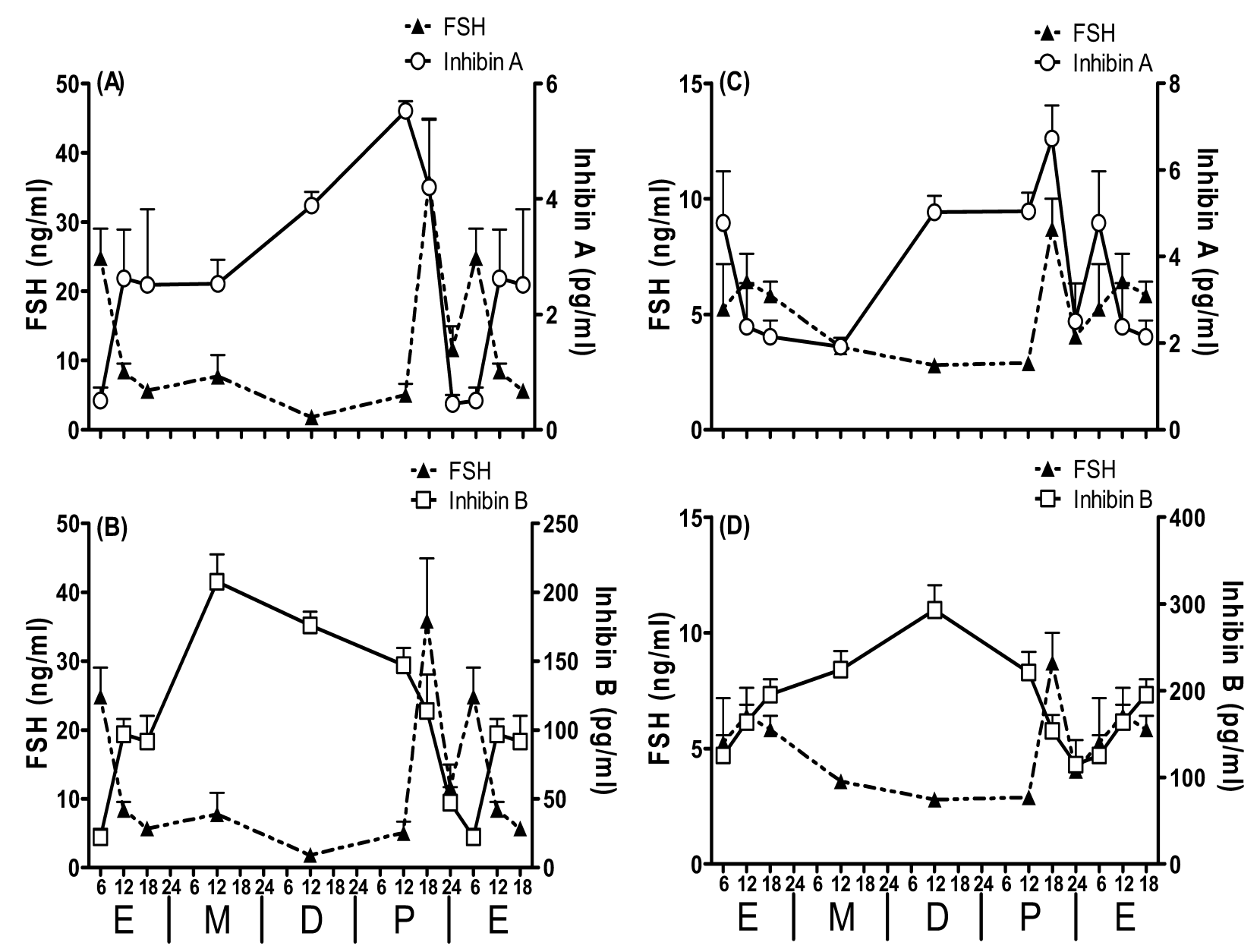

Time and stage of the estrous cycle

Fig. 2. The relationship between ( $\mathbf{\Delta})$ FSH and (o) inhibin A or ( $\square$ ) inhibin B during the estrous cycle in Hatano HAA (A, B) or LAA (C, D) rats. The stages of the estrous cycle are shown as $\mathrm{P}$ for proestrus, $\mathrm{E}$ for estrus, $\mathrm{M}$ for metestrus and D for diestrus. Data are shown as the mean \pm SEM and are derived from five rats.

those seen in mid proestrus (LAA) or late proestrus (HAA), respectively, as mentioned above (Fig. 1E).

\section{Contents of pituitary LH and FSH}

The changes in pituitary LH and FSH contents during the estrous cycle showed a similar pattern in both the HAA and LAA rats (Fig. 3). The pituitary contents of LH and FSH increased gradually after the preovulatory LH and FSH surge (Fig. 3). However, the mean pituitary contents of LH and FSH were high in HAA rats ( 2.8 to 5.9 -fold for LH and $\sim 1.4$ to 2.9 -fold for FSH) as compared with those of the LAA rats.

\section{LH and FSH secretions from primary cultured anterior pitu- itary cells}

To assess the low secretion of gonadotropins in LAA rats, the in vitro responsiveness of primary anterior pituitary cells to stimulation with GnRH was investigated. The basal release of $\mathrm{LH}$ and FSH by primary anterior pituitary cells was significantly lower in cells derived from the LAA rats than in those from HAA rats (Fig. 4A). Administration of $\mathrm{GnRH}\left(10^{-9}\right.$ to $\left.10^{-7} \mathrm{M}\right)$ resulted in a dose-dependent increase in LH and FSH secretion in HAA rats (Figs. 4A and 4B). However, although primary LAA rat anterior pituitary cells treated with GnRH exhibited an increase in their LH response, the concentrations of $\mathrm{LH}$ in the culture medium did not increase according to the doses of GnRH stimulation, and the LH secretion levels were lower in these LAA rat-derived pituitary cells than those seen in the HAA rat-derived cells. Moreover, in cells derived from the LAA rats, treatments with GnRH had no significant effect on FSH production, whereas a clear dose-dependent increase of FSH secretion was observed in those cells derived from HAA rats (Fig. 4B).

Numbers of preantral and antral follicles present during the estrous cycle

The average numbers of preantral and antral follicles are shown in Table 1. The average number of preantral follicles at $1200 \mathrm{~h}$ on 

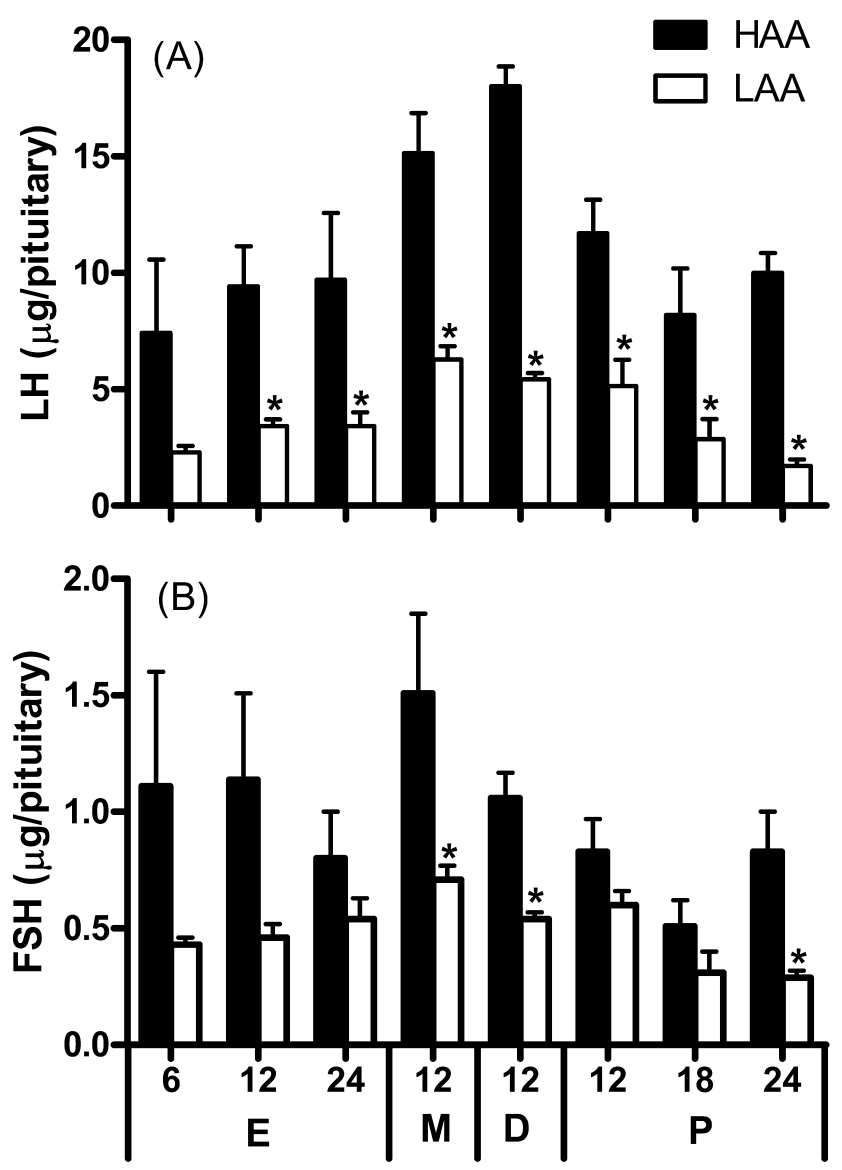

Fig. 3. Changes in pituitary contents of (A) LH and (B) FSH during the 4-day estrous cycle of female HAA and LAA rats. Values are the means \pm SEM of five observations. $* \mathrm{P}<0.05$ compared with HAA rats (Duncan's multiple comparison tests). The stages of the estrous cycle are shown as $\mathrm{P}$ for proestrus, E for estrus, $\mathrm{M}$ for metestrus and $\mathrm{D}$ for diestrus.
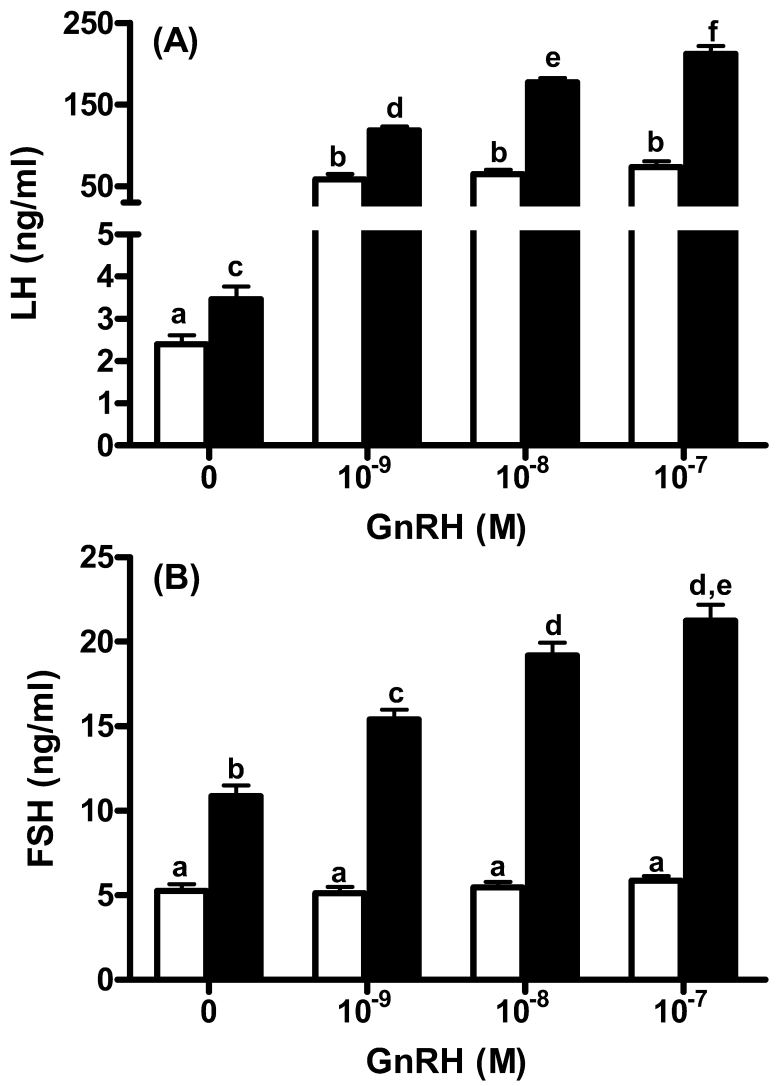

Fig. 4. Secretion levels of (A) LH and (B) FSH from primary cultured anterior pituitary gland cells derived from the Hatano (匹) HAA or (口) LAA rats with or without in vitro stimulation with the indicated concentrations of GnRH. Results represent the means \pm SEM of three different experiments performed in quintuplicate. The results were analyzed by two-way ANOVA and then by Duncan's multiple comparison tests. Different letters indicate significant differences $(\mathrm{P}<0.05)$.

Table 1. Distribution of healthy preantral and antral follicles in HAA and LAA rats at $1200 \mathrm{~h}$ during each stage of the estrous cycle

\begin{tabular}{clcc}
\hline Diameter of follicle & \multicolumn{1}{c}{ Stage } & HAA & LAA \\
\hline \multirow{3}{*}{$<300 \mu \mathrm{m}$ (Preantral) } & Metestrus & $90.4 \pm 9.14$ & $103.0 \pm 7.80$ \\
& Diestrus & $84.4 \pm 8.59$ & $144.8 \pm 13.15^{*}$ \\
& Proestrus & $22.0 \pm 3.96$ & $9.6 \pm 1.97^{*}$ \\
& Estrus & $13.0 \pm 2.70$ & $18.8 \pm 3.46$ \\
\hline \multirow{3}{*}{$300 \mu \mathrm{m}($ Antral $)$} & Metestrus & $20.6 \pm 3.38$ & $19.0 \pm 4.05$ \\
& Diestrus & $25.2 \pm 4.12$ & $25.4 \pm 3.36$ \\
& Proestrus & $23.8 \pm 6.28$ & $14.8 \pm 4.35$ \\
& Estrus & $22.0 \pm 4.85$ & $21.0 \pm 3.51$ \\
\hline \multirow{2}{*}{ Total } & Metestrus & $111.0 \pm 7.46$ & $122.0 \pm 7.91$ \\
& Diestrus & $109.6 \pm 10.43$ & $170.2 \pm 9.26^{*}$ \\
& Proestrus & $45.8 \pm 8.71$ & $24.4 \pm 4.38$ \\
& Estrus & $35.0 \pm 5.46$ & $39.8 \pm 2.90$
\end{tabular}

Data are shown as the mean \pm SEM number of follicle cells per ovary and are derived from five animals * $\mathrm{P}<0.05$ for LAA compared with HAA rats. 
Table 2. The average number of ovulated oocytes per rat after hCG treatment on the day of diestrus in HAA and LAA rats

\begin{tabular}{ccc}
\hline & HAA & LAA \\
\hline $\begin{array}{c}\text { Number of ovulated } \\
\text { oocytes }\end{array}$ & $\begin{array}{c}13.00 \pm 0.76 \\
(\mathrm{n}=8)\end{array}$ & $\begin{array}{c}11.17 \pm 0.17^{*} \\
(\mathrm{n}=6)\end{array}$ \\
\hline
\end{tabular}

Data are shown as means \pm SEM. The number of rats in each strain is indicated in parentheses. $* \mathrm{P}<0.05$ for LAA compared with HAA rats (independent $t$-test).

the day of diestrus was significantly $(\sim 1.7$-fold $)$ greater in LAA rats than that in HAA rats, while the average number of antral follicles did not significantly differ between the HAA and LAA rats. In contrast to other stages, the number of preantral follicles at $1200 \mathrm{~h}$ on the day of proestrus was significantly lower in LAA rats as compared with that in HAA rats. In addition, the number of antral follicles in LAA rats was also less on the day of proestrus than in HAA rats, but there were no significant differences in the other three stages of the estrous cycle.

\section{$h C G$-induced ovulation on the day of diestrus}

The average number of ovulated oocytes found per rat after hCG administration on the day of diestrus was significantly lower in LAA rats than that in HAA rats (Table 2).

\section{Immunolocalization of inhibin $\alpha-, \beta A$ - and $\beta B$-subunits in the} ovary during the estrous cycle

The immunoreactivity of inhibin $\alpha$ (Fig. 5, H1-4 and L1-4) was observed in the granulosa cells of preantral and antral follicles in both Hatano rat strains. The same pattern was also observed for the inhibin $\beta$ A (Fig. 5, H5-8 and L5-8) and inhibin $\beta$ B (Fig. 5, H9-12 and L9-12) subunits, in that there were no differences in the expression patterns of inhibin subunits between the rat strains throughout the estrous cycle. The granulosa cells of preovulatory follicles showed a high intensity of staining for all three inhibin subunits in proestrus, whilst the luteal cells showed negative staining for all inhibin subunits at all stages of the estrous cycle in both Hatano rat strains. The inhibin $\beta \mathrm{A}-$ and $\beta \mathrm{B}$-subunits were localized in granulosa cells of antral and some preantral follicles at estrus, metestrus and diestrus in both Hatano rat strains. At proestrus, the $\beta A$-subunit was no longer expressed by all antral follicles but was confined to healthy large antral follicles. Localization of the $\beta \mathrm{B}$ subunit in antral follicles was very low in proestrus, while strong expression of the $\alpha$ - and $\beta$ A-subunits was observed in antral follicles at this time. At the proestrous stage, staining for the inhibin $\alpha-, \beta A-$ and $\beta B$-subunits confirmed that very few antral follicles remained in the LAA ovaries.

\section{Discussion}

The present study demonstrated that the two inbred strains of Hatano rats, HAA and LAA, showed clear strain differences in the hypothalamic-pituitary axis, the glands that play an important role in the regulation of ovarian function during the estrous cycle. LAA rats have low basal and surge levels of LH and FSH but high levels of inhibin A and inhibin B throughout the estrous cycle when com- pared with the levels observed in HAA rats. Thus, in the LAA rats, the high levels of inhibin A and B may strongly suppress the secretion of FSH from the pituitary gland throughout the estrous cycle. In the present study, the pituitary contents of LH and FSH in LAA rats were also lower than those seen in HAA rats, indicating that syntheses of these gonadotropins in the gonadotroph cells were low in LAA rats probably due to low levels of $\mathrm{GnRH}$ secretion from the hypothalamus.

On the other hand, the finding of differential FSH and LH levels between the HAA and LAA strains may have considerable implications for the diminishment of anterior pituitary responsiveness to GnRH, since FSH and LH secretion are under the control of hypothalamic GnRH [12]. Thus, the responsiveness of the anterior pituitary cells to GnRH was used to compare the ability of gonadotropes to initiate the release of gonadotropins between HAA and LAA rats. Cultured primary anterior pituitary cells from LAA rats, but not those from HAA rats, showed a low in vitro basal ability to secrete $\mathrm{LH}$ and $\mathrm{FSH}$, and moreover, following stimulation by $\mathrm{GnRH}$, the LAA-derived cells showed a weaker increase in LH secretion levels and no increased FSH secretion in contrast to that seen with the HAA-derived cell cultures. Thus, there is a clear strain difference in the regulatory system of GnRH, LH and FSH between the two Hatano rat strains. The present study clearly demonstrated that the anterior pituitary cells of LAA rats are less sensitive to GnRH than those from HAA rats.

During the periovulatory period, there are two FSH surges in rats [2] and golden hamsters [8]. In the female rat, the first FSH surge was observed in the afternoon of the day of proestrus, and the preovulatory LH surge occurred at the same time. On the other hand, the secondary FSH surge occurred in the early morning on the day of estrus, just after ovulation without the LH surge [2]. It was speculated that the first FSH surge was induced by the preovulatory GnRH surge and that the secondary FSH surge was induced by the abrupt decline in circulating inhibins [13]. Both FSH surges are important for development of a new wave of follicles. In the present study, the secondary FSH surge was observed, and the negative correlation between the secondary FSH surge and bioactive inhibins (inhibin A or inhibin B) was clearly demonstrated during the periovulatory period in HAA rats, whereas the secondary FSH surge was lacking in LAA rats. Although the reason for the lack of a secondary FSH surge in LAA rats is not clear at the present time, the high levels of circulating inhibin A and inhibin B are probably involved in the mechanism responsible for suppressing the secondary FSH surge.

Previous reports have shown that HAA rats ovulate more oocytes than LAA rats [2, 14], and it is well known that follicular development in mammals is controlled by the two pituitary-derived glycoprotein hormones, FSH and LH [15]. During follicular development, most follicles undergo atretic degeneration, whereas a few of them, under stimulation from cyclic gonadotropins, reach the preovulatory stage $[16,17]$. FSH is an essential survival hormone for prevention of the programmed demise of early antral follicles in mammals [16-18], whilst LH is also important in the final differentiation of granulosa cells in antral and preovulatory follicles to allow the biosynthesis of estrogens and to prepare the preovulatory follicles for ovulation $[19,20]$. Furthermore, LH operates in 

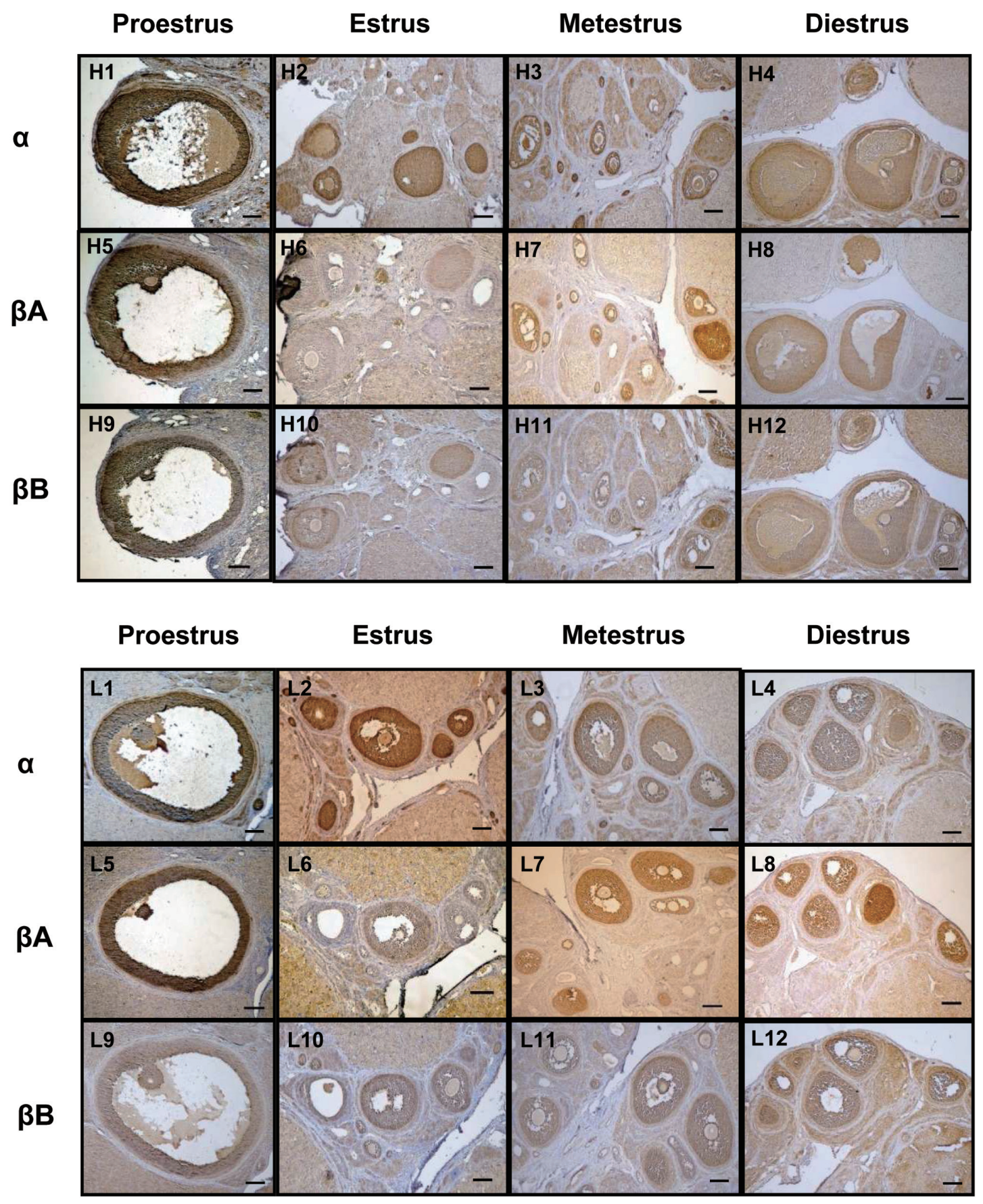

Fig. 5. Immunolocalization of ovarian inhibin $\alpha-, \beta A$ - and $\beta B$-subunits in Hatano HAA (H1-12) and LAA (L1-12) rats during the proestrous, estrous, metestrous and diestrous stages of the estrous cycle. Each image is representative of least three other sections, and each bar represents $50 \mu \mathrm{m}$.

synergy with FSH to ensure follicular maturation and secretion of adequate amounts of estradiol-17 $\beta$ [21]. Testosterone production by the theca interna cells is a function of LH, whereas FSH controls the aromatization of this testosterone to estradiol-17 $\beta$ by granulosa cells [22]. In accordance with this, reduction of the serum levels of FSH and LH in juvenile rats, by either hypophysectomy or GnRH antagonist treatment, resulted in a decreased ovarian weight, a reduced number of developing follicles and increased atresia of the remaining follicles [23]. In addition, the basal secretion of FSH during the rat estrous cycle was shown to play an essential role in follicular development and maturation towards ovulation [24]. Thus, the low basal LH levels and low FSH surges in LAA rats 
likely reduce the number of antral follicles and ovulated oocytes compared with HAA rats, and this is consistent with the results reported here.

The distinct patterns of inhibin A and inhibin B secretion observed across the estrous cycle [8, 25-27] and their relationship to $\mathrm{LH}$ and FSH secretion suggest that the regulation of inhibin $\mathrm{A}$ and inhibin B secretion is dependent on the stage of follicular cell development. The difference in inhibin A and inhibin B secretion during the estrous cycle between the two Hatano strains was originally thought to be due to different populations of follicles secreting inhibin A and inhibin B. The present study shows that all follicles are capable of producing both inhibin isoforms and that disparity in a single follicle's granulosa cell population is the basis for the temporal differences in inhibin A and inhibin B secretion into the circulation. Indeed, inhibin B was reported to be the most sensitive marker for proliferation of early stage follicles, while inhibin A secretion becomes predominant at later stages [28]. Thus, the changes in the concentration of inhibin A likely reflect the number of large antral follicles in the ovary. On the other hand, the secretion of inhibin B from developing follicles would be reduced, and the smaller follicles might be responsible for the secretion of inhibin $\mathrm{B}$, especially in the morning of diestrus and proestrus. Here, the present study found that LAA rats had a higher concentration of circulating inhibin B throughout the estrous cycle and especially during diestrus, whereas FSH and LH surges in the LAA rats were lower than in the HAA rats. The preantral follicles at $1200 \mathrm{~h}$ of diestrus were more numerous in LAA rats but were less numerous during proestrus when compared with the number observed in HAA rats.

The plasma concentrations of estradiol-17 $\beta$ were significantly lower in LAA rats than HAA rats during proestrus. These results suggest that LAA rats may have much more follicle growth during the early stage of folliculogenesis but that they have a lower number of mature follicles compared with that seen in HAA rats due to the low level of gonadotropins. In support of this hypothesis, a significant difference was observed in hCG-induced ovulation in the present study. Although there were no statistical differences in the numbers of antral follicles between the two rat strains, the number of ovulated oocytes after hCG administration during diestrus was significantly lower in the LAA rats than in the HAA rats, indicating that the number of mature large antral follicles was lower in the LAA rats compared with the HAA rats. These studies clearly indicate that LAA rats may have more follicle growth during the early stage of folliculogenesis, but most follicles might not grow into mature follicles.

In addition, the concentrations of plasma progesterone remained constantly higher in LAA rats than in HAA rats during the estrous cycle. Our previous paper showed that the number of corpora lutea was larger in LAA rats than in HAA rats [2]. These differences correspond to the luteal function and follicular maturation in both strains. A previous report clearly showed that a single subcutaneous injection of progesterone at $0900 \mathrm{~h}$ during diestrus causes a precipitous decline in circulating LH and FSH associated with a decline in circulating estradiol-17 $\beta$ within $1 \mathrm{~h}$ after injection of progesterone [21]. Similar results with regard to circulating LH and estradiol-17 $\beta$ after progesterone injection in the rat have been re- ported in golden hamsters [29]. Exogenous progesterone injected during diestrus in the estrous cycle of the golden hamster selectively reduced serum LH, which in turn, decreased estradiol-17 $\beta$ secretion within $1 \mathrm{~h}$. The rapid diminutions in estradiol-17 $\beta$ secretion were reversible in the golden hamster by the administration of hCG or LH [29]. Administration of progesterone reduces the output of $\mathrm{GnRH}$ produced by electrical stimulation of the medial preoptic area [30] or reduces GnRH concentrations in pituitary stalk blood in acutely ovariectomized and estradiol benzoate-treated rats [31]. Progesterone also inhibits the firing rate of single hypothalamic units, both spontaneous and evoked [32-35], and extinguishes the daily neural signal for LH release [36]. A previous paper also demonstrated that the inhibition of LH pulse frequency by progesterone occurred through an acute neural modulation of GnRH release in ewes and that this modulation involves a direct effect of progesterone on the nuclear progesterone receptor system [37]. In the present study, it is likely, therefore, that the high levels of progesterone in LAA rats affect the neural mechanisms regulating the secretion of $\mathrm{LH}$, which is responsible for follicular maturation.

The present study strongly suggests that the low follicular function in LAA rats is due to the low ability of the hypothalamic-pituitary axis. These results also indicate that the Hatano HAA and LAA rat strains are a useful animal model for investigating the mechanisms responsible for secretion of $\mathrm{LH}$ and FSH and follicular development in the mammalian ovary.

\section{Acknowledgments}

We are grateful to Dr AF Parlow and the NIDDK (Harbor-UCLA Medical Center, Torrance, CA, USA) for providing the RIA materials for the rat LH and FSH assay, GD Niswender (Animal Production and Biotechnology, Colorado State University, Fort Collins, CO, USA) for providing antisera to progesterone (GDN337) and estradiol-17 $\beta$ (GDN244), Dr N Ling (Neuroendocrine) for providing [Tyr 30] inhibin- $\alpha-(1-30)$ and Dr W Vale (Clayton Foundation for Peptide Biology, Salk Institute for Biological Studies) for providing antisera against inhibin- $\beta A$ and inhibin- $\beta B$. This study was supported in part by a Grant-in-Aid for Scientific Research (The Japan-Thailand Joint Research) from the Japan Society for the Promotion of Science.

\section{References}

1. Ohta R, Shirota M, Adachi T, Tohei A, Taya K. Plasma ACTH levels during early, two-way avoidance acquisition in high- and low- avoidance rats (Hatano strains). Behavior Genetics 1999; 29: 137-144. [Medline] [CrossRef]

2. Asai S, Ohta R, Shirota M, Sato M, Watanabe G, Taya K. Reproductive endocrinology in Hatano high- and low-avoidance rats during the estrous cycle. Endocrine 2002; 18: 161-166. [Medline] [CrossRef]

3. Asai S, Ohta R, Shirota M, Tohei A, Watanabe G, Taya K. Endocrinological responses during suckling in Hatano high- and low-avoidance rats. J Endocrinol 2004; 182: 267-272. [Medline] [CrossRef]

4. Taya K, Greenwald GS. Mechanisms of suppression of ovarian follicular development during lactation in the rat. Biol Reprod 1982; 27: 1090-1101. [Medline] [CrossRef]

5. Shi F, Ozawa M, Komura H, Yang P, Trewin AL, Hutz RJ, Watanabe G, Taya K. Secretion of ovarian inhibin and its physiologic roles in the regulation of folliclestimulating hormone secretion during the estrous cycle of the female guinea pig. Biol Reprod 1999; 60: 78-84. [Medline] [CrossRef]

6. Kandiel MM, Watanabe G, Sosa GA, Abou El-Roos ME, Abdel-Ghaffar AE, Li 
JY, Manabe N, El Azab Ael S, Taya K. Profiles of circulating steroid hormones, gonadotropins, immunoreactive inhibin and prolactin during pregnancy in goats and immunolocalization of inhibin subunits, steroidogenic enzymes and prolactin in the corpus luteum and placenta. J Reprod Dev 2010; 56: 243-250. [Medline] [CrossRef]

7. Taya K, Sasamoto S. Induced development of ovulatory follicles during the early stages of lactation by the administration of LH in the rat. J Endocrinol 1988; 116: 115122. [Medline] [CrossRef]

8. Ohshima K, Kishi H, Itoh M, Watanabe G, Arai K, Uehara K, Groome NP, Taya K. Secretion of inhibin A, inhibin B and inhibin pro-alphaC during the oestrous cycle of the golden hamster (Mesocricetus auratus). J Endocrinol 1999; 162: 451-456. [Medline] [CrossRef]

9. Groome NP, Lawrence M. Preparation of monoclonal antibodies to the beta A subunit of ovarian inhibin using a synthetic peptide immunogen. Hybridoma 1991; 10 309-316. [Medline] [CrossRef]

10. Groome NP, Illingworth P, O'Brien M, Pai R, Rodger FE, Mather J, McNeilly A. Measurement of dimeric inhibin B throughout the human menstrual cycle. J Clin Endocrinol Metab 1996; 81: 1401-1405. [Medline] [CrossRef]

11. Taya K, Watanabe G, Sasamoto S. Radioimmunoassay for progesterone, testosterone and estradiol-17 $\beta$ using ${ }^{125}$ I-iodohistamine radioligands. Jpn J Anim Reprod 1985; 31: 186-197.

12. Belchetz PE, Plant TM, Nakai Y, Keogh EJ, Knobil E. Hypophysial responses to continuous and intermittent delivery of hypopthalamic gonadotropin-releasing hormone. Science 1978; 202: 631-633. [Medline] [CrossRef]

13. Arai KY, Watanabe G, Arai K, Uehara K, Taya K. Contribution of endogenous inhibin to the decline of the secondary surge of follicle-stimulating hormone in the rat. Reprod Fertil Dev 2001; 13: 203-209. [Medline] [CrossRef]

14. Shirota M, Sato M, Kojima K, Ohta R. Minor involvement of somatic growth in the onset of puberty of Hatano high- and low-avoidance rats. Reproduction 2004; 127: 389-395. [Medline] [CrossRef]

15. Richards JS. Maturation of ovarian follicles: actions and interactions of pituitary and ovarian hormones on follicular cell differentiation. Physiol Rev 1980; 60: 51-89. [Medline]

16. Hirshfield AN. Development of follicles in the mammalian ovary. Int Rev Cytol 1991; 124: 43-101. [Medline] [CrossRef]

17. Hsueh AJ, Billig H, Tsafriri A. Ovarian follicle atresia: a hormonally controlled apoptotic process. Endocr Rev 1994; 15: 707-724. [Medline]

18. Chun SY, Eisenhauer KM, Minami S, Hsueh AJ. Growth factors in ovarian follicle atresia. Semin Reprod Endocrinol 1996; 14: 197-202. [Medline] [CrossRef]

19. Hsueh AJ, Adashi EY, Jones PB, Welsh TH Jr. Hormonal regulation of the differentiation of cultured ovarian granulosa cells. Endocr Rev 1984; 5: 76-127. [Medline] [CrossRef]

20. Arai K, Ohshima K, Watanabe G, Arai K, Uehara K, Taya K. Inhibition of ovarian follicular development associated with a decrease in luteinizing hormone levels during the estrous cycle of the rat. Endocr J 1998; 45: 539-546. [Medline] [CrossRef]

21. Taya K, Terranova PF, Greenwald GS. Acute effects of exogenous progesterone on follicular steroidgenesis in the cyclic rat. Endocrinology 1981; 108: 2324-2330. [Medline] [CrossRef]

22. Armstrong DT, Dorrington JA. Regulatory mechanisms affecting gonadal hormone action. In: Advances in Sex Hormone Research. Baltimore, MD: Univ. Park Press,
1977; 2: 217-258.

23. Hsueh AJ, McGee EA, Hayashi M, Hsu SY. Hormonal regulation of early follicle development in the rat ovary. Mol Cell Endocrinol 2000; 163: 95-100. [Medline] [CrossRef]

24. Noguchi J, Watanabe G, Taya K, Sasamoto S. Suppression of basal secretion of FSH inhibits follicular development and maturation during the oestrous cycle of the rat. J Endocrinol 1993; 139: 287-293. [Medline] [CrossRef]

25. McLachlan RI, Robertson DM, de Kretser D, Burger HG. Inhibin-a non-steroidal regulator of pituitary follicle stimulating hormone. Baillieres Clin Endocrinol Metab 1987; 1: 89-112. [Medline] [CrossRef]

26. Ohshima K, Kishi H, Itoh M, Arai KY, Watanabe G, Arai K, Uehara K, Groome NP Taya K. Secretory pattern of inhibin A, inhibin B and inhibin pro-alpha $C$ during induced follicular atresia and subsequent follicular development in the golden hamster (Mesocricetus auratus). J Endocrinol 2002; 172: 575-581. [Medline] [CrossRef]

27. Woodruff TK, Besecke LM, Groome N, Draper LB, Schwartz NB, Weiss J. Inhibin $\mathrm{A}$ and inhibin $\mathrm{B}$ are inversely correlated to follicle-stimulating hormone, yet are discordant during the follicular phase of the rat estrous cycle, and inhibin $\mathrm{A}$ is expressed in a sexually dimorphic manner. Endocrinology 1996; 137: 5463-5467. [Medline] [CrossRef]

28. Smitz J, Cortvrindt R. Inhibin A and B secretion in mouse preantral follicle culture. Hum Reprod 1998; 13: 927-935. [Medline] [CrossRef]

29. Greenwald GS. Modification by exogenous progesterone of estrogen and gonadotropin secretion in the cyclic hamster. Endocrinology 1978; 103: 2315-2322. [Medline] [CrossRef]

30. Sherwood NM, Chiappa SA, Fink G. Immunoreactive luteinizing hormone releasing factor in pituitary stalk blood from female rats: sex steroid modulation of response to electrical stimulation of preoptic area or median eminence. J Endocrinol 1976; 70: 501-511. [Medline] [CrossRef]

31. Sarkar DK, Fink G. Effects of gonadal steroids on output of luteinizing hormone releasing factor into pituitary stalk blood in female rat. J Endocrinol 1979; 80: 303-313. [Medline] [CrossRef]

32. Cross BA. Unit responses in the hypothalamus. In: Ganong WF, Martini L (eds.) Frontiers in Neuroendocrinology. University Press, Oxford, 1973; 133-171.

33. Negoro H, Visessuwan S, Holland RC. Unit activity in the paraventricular nucleus of female rats at different stages of the reproductive cycle and after ovariectomy, with or without oestrogen or progesterone treatment. J Endocrinol 1973; 59: 545-558. [Medline] [CrossRef]

34. Negoro H, Visessuwan S, Holland RC. Reflex activation of paraventricular nucleus units during the reproductive cycle and in ovariectomized rats treated with oestrogen or progesterone. J Endocrinol 1973; 59: 559-567. [Medline] [CrossRef]

35. Hayward JN. Functional and morphological aspects of hypothalamic neurons. Physiol Rev 1977; 57: 574-658. [Medline]

36. Freeman MC, Dupke KC, Croteau CM. Extinction of the estrogen induced daily signal for LH release in the rats; a role for the proestrous surge of progresterone. Endocrinology 1976; 99: 223-229. [Medline] [CrossRef]

37. Skinner DC, Evans NP, Delaleu B, Goodman RL, Bouchard P, Caraty A. The negative feedback actions of progesterone on gonadotropinreleasing hormone secretion are transduced by the classical progesterone receptor. Proc Natl Acad Sci USA 1998; 95: 10978-10983. [Medline] [CrossRef] 